\title{
AOR
}

Selected Papers of \#AolR2019:

The $20^{\text {th }}$ Annual Conference of the Association of Internet Researchers Brisbane, Australia / 2-5 October 2019

\section{FANGIRLS AND FAKE NEWS: DIGITAL ETHNOGRAPHY AND THE AFFECTS OF FANDOM}

\author{
Hannah McCann \\ University of Melbourne \\ Clare Southerton \\ Aarhus University
}

\section{Introduction}

With the development of various digital platforms, participating in fandom has transformed from a niche practice to a mainstream activity that forms an integral part of daily life for many young people (Gray, Sandvoss and Harrington 2017). This paper draws on a digital ethnography conducted via Twitter, of a controversial subnetwork of fans of boyband One Direction known as "Larries". Through digital ethnographic methods, we explore how - in contrast to their controversial popular media framing the practices of Larries create a space in which new and unexpected desires, identities, intimacies and relations are constituted. We use this study to consider the benefits of undertaking qualitative digital ethnographic work and discuss the affective flows of digital networks on social media that might remain obscured by other digital methods.

The Larry fandom is built around imagining a romantic relationship exists between One Direction band members Harry Styles and Louis Tomlinson, referred to by the portmanteau "Larry". Imagining relationships between celebrities is a controversial practice known in fan communities as "Real Person Slash" (RPS). For this practice Larries have been framed within popular media as "tin hat" conspiracy theorists (Jones 2016). Sites such as Junkee, Vox and Buzzfeed have called Larries "truthers" (Romano 2016) and "conspirators" (Romanoff 2018) who inhabit a "post-truth" world (Carvan 2018). Given this "fake news" framing, our study sought to examine whether a more complex and nuanced understanding of the fandom was possible, particularly regarding the relationships and community building that might occur in this fandom.

Suggested Citation (APA): McCann, H. \& Southerton, C. (2019, October 2-5). Fangirls And Fake News: Digital Ethnography And The Affects Of Fandom. Paper presented at AolR 2019: The $20^{\text {th }}$ Annual Conference of the Association of Internet Researchers. Brisbane, Australia: AolR. Retrieved from http://spir.aoir.org. 


\section{Digital Ethnography and Ethical Considerations}

Our digital ethnography consisted of observation, participation, and interviews, in order to gain an embedded understanding of digital practices (Hine 2015, Simonetto 2016). We set up an account on Twitter for the project in order to conduct observations and interviews. We quickly found that searching via hashtags on Twitter did not lead us to accounts - the controversial nature of the fandom means that they avoid using easily identifiable hashtags given the public scrutiny that they have been subject to. Instead, we spent approximately two months reading about and learning the language of the fandom which included emojis and other coded signifiers. Between March and July 2018, we followed approximately 490 public accounts dedicated to the Larry fandom, keeping a fieldnote diary. The purpose of ethnographic observation is "to investigate, experience and represent the social life and social processes that occur in that setting" (Emerson, Fretz and Shaw 2001, 352). We also conducted semi-structured interviews with seven active users, via direct messenger, maintaining the digitally mediated ways that fans interact in this space (Kazmer and Xie 2008).

Setting up our research account required complex ethical considerations around explicit identification of the project while still allowing for embedding within the fan community. Furthermore, while some scholars argue that with publicly available reflections online "the only restriction is not to misquote" (Hoser and Nitschke 2010,186), others suggest that there are more complex expectations of privacy in these spaces (Busse and Hellekson 2012). Given the controversial nature of the fandom, where fear over misrepresentation is heightened, we deferred to de-identification as a key strategy, and the need for consent for the replication of any direct materials.

\section{Findings}

Our study revealed the ways that the Larry fandom establishes a semi-private space on the seeming public Twitter platform, continually building collective knowledge by circulating images, gifs, and old tweets, as well as through the use of highly specific insider language. The space was dynamic, subject to sudden activity following news or discussions initiated from within. As Caitlin Byrne notes, "[The] continual, communal sharing and shaping of information makes social media a fascinating area of study for qualitative researchers" $(2017,799)$. Indeed, we found that the micro-blogging specifics of Twitter, and its repetitive and re-circulatable content dimensions that are both textbased and visual, make it an ideal space within which to conduct digital ethnography as it necessitates attunement to the affective flows of the space. Conducting observations on a daily basis over an extended period as regular fans would, we became privy to the highs, lows, excitement, and tensions of the group, that may be otherwise obscured through analysis such as "crowd dynamics" (Arvidsson 2014).

Previous research has found that the focus of fandoms can act as a kind of "cultural resource" for fans (Stevenson 2009). Similarly, our findings suggest that friendship, trust, and a sense of intimacy is made available through the Larry fandom. Indeed, the fandom appears to provide a resource for celebrating non-normative sexualities, without necessitating participants to personally identify their own sexuality. In other words, the Larry fandom provides a space to celebrate sexuality, without drawing strict identity boundaries. Furthermore, while some regard the fandom as "conspiracy theorists", the practices of these fans reveal challenges to heteronormative representations of 
celebrities and subversion of expectations of the desires of fangirls. This raises questions about what might be missed in studying controversial groups at a macro level only, given the quality of the practices of the group - whether "fake news" or not, these fans represent a challenge to the dominant (sexual) paradigm.

\section{References}

Arvidsson, A. (2014, October 22-24). Collaborative Crowding, A Digital Ethnography of Adolescent Fan Cultures on Twitter. Paper presented at The 15th Annual Meeting of the Association of Internet Researchers. Daegu, Korea. Retreived from http://spir.aoir.org.

Busse, K. and Hellekson, K. (2012). "Identity, Ethics, and Fan Privacy." In Fan Culture: Theory/Practice, Katherine Larsen and Lynn Zubernis (Eds.), Newcastle: Cambridge Scholars Publishing, 38-56.

Byrne, C. (2017). "Anonymous Social Media and Qualitative Inquiry: Methodological Considerations and Implications for Using Yik Yak as a Qualitative Data Source." Qualitative Inquiry, 23(10) 799-807.

Carvan, Tabitha. 2018. "One Direction, Fake Babies and The Problem with Celebrity Conspiracy Theories." Junkee, April 17. http://junkee.com/celebrityconspiracy-theories $/ 154327$

Emerson, R., Fretz, R. and Shaw, L. (2001). "Participant Observation and Fieldnotes". In Handbook of Ethnography, Paul Atkinson, Amanda Coffey, Sara Delamont, John Lofland \& Lyn Lofland (Eds.), SAGE, 352-368.

Gray, J., Sandvoss, C. and Harrington, C.L. (2017). Fandom: Identities and communities in a mediated world. New York: New York University Press.

Hine, C. (2015). Ethnography for the Internet: Embedded, Embodied and Everyday. London: Bloomsbury Publishing.

Hoser, B., and Nitschke, T. (2010). "Questions on ethics for research in the virtually connected world," Social Networks, 32: 180-186.

Jones, B. (2016). "'I Will Throw You Off Your Ship and You Will Die': Death Threats, Intra-Fandom Hate and the Performance of Fangirling." In Seeing Fans: Representations of Fandom in Media and Popular Culture, ed. Lucy Bennett and Paul Booth, 53-65. London: Bloomsbury.

Kazmer , M. M. \& Xie, B. (2008). "Qualitative Interviewing in Internet Studies: Playing with the media, playing with the method." Information, Community and Society, 11:2, 257-278.

Romano, A. (2016). "Larry Stylinson, the One Direction conspiracy theory that rules the internet, explained." Vox, 18 April.

https://www.vox.com/2016/4/18/11384118/larry-stylinson-one-directionconspiracy-theory

Romanoff, Z. (2018). "A Journey into the Dark Heart of Celebrity Relationship Conspiracy Theories." Buzzfeed, 3 July. https://www.buzzfeed.com/amphtml/zanromanoff/celebrity-conspiracy-theoriesharry-styles-louis-tomlinson

Simonetto, D. (2016). "Expanding Our Methodological Toolbox: The' Place' of Twitter in the Ethnographic Endeavor." Qualitative Sociology Review, 12(1): 98-112.

Stevenson, N. (2009). "Talking to Bowie Fans: Masculinity, Ambivalence and Cultural Citizenship." European Journal of Cultural Studies, 12(1): 79-98. 